\title{
Tingkat Kepuasan Pemustaka di Dinas Perpustakaan dan Kearsipan Kota Solok: Analisis Libqual+TM
}

\author{
Cherly Pratiwi \\ Universitas Negeri Padang \\ E-mail: cherlypratiwii1210@gmail.com
}

Received: 13-12-2021

Revised: 21-12-2021

Accepted: 25-12-2021

DOI: $10.24036 /$ ib.v3i1.264

\begin{abstract}
This study discusses the level of user satisfaction of the Solok City Library and Archives Service which was analyzed using Libqual+Tm. Libqual+Tm. Consists of three dimensions, namely affect of service, information control and library as place. The purpose of this study is to describe the level of user satisfaction at the Solok City Library and Archives Service. This research is a quantitative research with descriptive method. Data collection techniques through interviews and questionnaires. The research data was obtained from distributing questionnaires to the users of the Solok City Library and Archives Service as a population. Sampling from the study using incidental sampling technique and obtained a sample of 50 people. Based on the results of the study, the following conclusions were drawn: (1) based on the dimensions of the officer's performance in serving (affect of service) the users felt quite satisfied with the Adequacy Gap $(A G)$ the dimension was positive with a score of 0.05 and the level of user satisfaction with the library was considered very satisfied. with the Superiority Gap (SG) is positive with a score of 0.52; (2) based on the dimensions of information quality and access to information (information control) the users are not satisfied with the Adequacy Gap (AG), the dimension is negative with a score of -0.20 and the level of user satisfaction with the library is considered very satisfied with the Superiority Gap (SG) is positive with score 0.25; (3) based on the dimensions of library facilities and infrastructure (library as place) the users are quite satisfied with the Adequacy Gap (AG) with a value dimension of 0.013 and the level of user satisfaction with the library is considered very satisfied with the Superiority Gap (SG) with a positive value with a score of 0.50. Overall, the level of user satisfaction, the level of satisfaction of the users of the Library and Archives Service of Solok City, the users are quite satisfied with the average Adequacy Gap (AG) is positive with a score of 0.08 and the level of user satisfaction with the library is considered very satisfied with the average Superiority (SG). positive value with a score of 0.4.
\end{abstract}

Keywords: satisfaction; Libqual+TM; library

\begin{abstract}
Abstrak
Penelitian ini membahas mengenai tingkat kepuasan pemustaka Dinas Perpustakaan dan Kearsipan Kota Solok yang dianalisis menggunakan Libqual+Tm. Libqual+Tm. Terdiri dari tiga dimensi yaitu affect of service, information control dan library as place. Tujuan penelitian ini yaitu, mendeskripsikan tingkat kepuasan pemustaka di Dinas Perpustakaan dan Kearsipan Kota Solok. Penelitian ini merupakan penelitian kuantitatif dengan metode deskriptif. Teknik pengumpulan data melalui wawancara dan kuesioner. Data penelitian diperoleh dari penyebaran kuesioner pada pemustaka Dinas Perpustakaan dan Kearsipan Kota Solok sebagai populasi. Penarikan sampel dari penelitian menggunakan teknik sampling insidental dan diperoleh sampel sebanyak 50 orang. Berdasarkan hasil penelitian maka ditarik kesimpulan sebagai berikut: (1) berdasarkan dimensi kinerja petugas dalam melayani (affect of service) pemustaka merasakan cukup puas dengan Adequacy Gap (AG) dimensi bernilai positif dengan skor 0,05 dan tingkat kepuasan pemustaka terhadap perpustakaan dinilai sangat puas dengan Superiority Gap (SG) bernilai positif dengan skor 0,52; (2) berdasarkan dimensi kualitas informasi dan akses informasi (information control) pemustaka belum puas dengan Adequacy Gap (AG) dimensi bernilai negatif dengan
\end{abstract}


Published by Program Studi Perpustakaan dan Ilmu Informasi

FBS Universitas Negeri Padang, Indonesia

skor -0,20 dan tingkat kepuasan pemustaka terhadap perpustakaan dinilai sangat puas dengan Superiority Gap (SG) bernilai positif dengan skor 0,25; (3) berdasarkan dimensi sarana dan prasarana perpustakaan (library as place) pemustaka cukup puas dengan Adequacy Gap (AG) dimensi bernilai dengan skor 0,013 dan tingkat kepuasan pemustaka terhadap perpustakaan dinilai sangat puas dengan Superiority Gap (SG) bernilai positif dengan skor 0,50. Secara keseluruhan tingkat kepuasan pemustaka tingkat kepuasan pemustaka Dinas Perpustakaan dan Kearsipan Kota Solok pemustaka cukup puas dengan rata-rata Adequacy Gap (AG) bernilai positif dengan skor 0,08 dan tingkat kepuasan pemustaka terhadap perpustakaan dinilai sangat puas dengan rata-rata Superiority Gap (SG) bernilai positif dengan skor 0,4 .

Kata kunci: kepuasan; Libqual+TM; perpustakaan

\section{PENDAHULUAN}

Perpustakaan yang dapat dikatakan baik adalah perpustakaan yang dapat memenuhi kebutuhan pemustaka dan menjaga kenyamanan pemustaka serta menjaga loyalitasnya untuk berkunjung ke perpustakaan. Keberadaan perpustakaan diharapkan dapat membantu dalam kelancaran pemustaka dalam mencari informasi yang diinginkan melalui penyediaan koleksi yang memadai dan berbagai fasilitas penunjang yang lengkap agar pemustaka nyaman di dalam perpustakaan.

Sebagai perpustakaan umum, Dinas Perpustakaan dan Kearsipan Kota Solok berada di bawah naungan Pemerintah Kota Solok yang beralamat di Jl. Lubuk Sikarah No.89 Komplek Kantor Walikota Solok, Kota Solok. Perpustakaan ini berfungsi sebagai pusat informasi bagi masyarakat Kota Solok. Perpustakaan ini memiliki berbagai fasilitas seperti pada perpustakaan umumnya, tetapi dalam implementasinya masih terdapat beberapa kekurangan. Dari data yang didapat melalui pustakawan terdapat 9584 eksemplar dan jumlah anggota yang telah terdaftar di Perpustakaan dan Kearsipan Kota Solok kisaran dari tahun 2010 hingga tahun 2020 sebanyak 8.126 orang. Berdasarkan hasil observasi awal berupa wawancara yang dilakukan penulis dengan lima orang pemustaka pada hari Jumat, 5 Februari 2021, wawancara ini bertujuan untuk mengetahui pendapat pemustaka terhadap fasilitas dan kenyamanan yang ada di perpustakaan tersebut. Dari hasil wawancara, pemustaka berpendapat bahwa perpustakaan yang dijalankan terkesan 
Published by Program Studi Perpustakaan dan Ilmu Informasi

"yang penting ada dan yang penting beroperasi" karena kurangnya perhatian terhadap pengadaan dan pemeliharaan koleksi bahan pustaka yang ada, fasilitas yang terbatas, dan kurangnya pelayanan yang maksimal diakibatkan kurangnya tenaga perpustakaan yang berlatar belakang pustakawan. Dari hasil wawancara terdapat permasalahan yang dialami, salah satunya koleksi yang tidak memadai untuk pemustaka dan pemustaka juga menyebutkan bahwa koleksi yang tidak diperbarui oleh pustakawan yang menyebabkan pemustaka kesulitan mencari bahan koleksi yang diinginkannya.

Berdasarkan permasalahan tersebut, penulis tertarik melakukan pengukuran tingkat kepuasan pemustaka terhadap kualitas layanan di Dinas Perpustakaan dan Kearsipan Kota Solok dengan metode Libqual+TM. Menurut Faidah \& Rachman (2016) menyampaikan Libqual+TM dicetus dalam tahun 1999 sang para ahli pada bidang ilmu perpustakaan \& fakta yg tergabung pada ARL (Association Research Library) pada Amerika
Serikat berafiliasi menggunakan Texas A\&M University, sesudah melalui kajian yg lama. Metode ini dipercaya paling terkini \& sekarang dipakai sang hampir semua perpustakaan pada Amerika Serikat, Eropa, United Kingdom, \& Australia. Layanan perpustakaan nir akan berkualitas bila terdapat kepuasan berdasarkan pemustaka. Dengan demikian hasil penelitian ini dapat menjadi pedoman bagi Dinas Perpustakaan dan Kearsipan Kota Solok dalam meningkatkan kualitas layanan terhadap kepuasan pemustaka agar pemustaka senantiasa berkunjung ke perpustakaan dengan rasa nyaman dan puas, sehingga harapan pemustaka sesuai dengan kenyataan yang diinginkan.

\section{METODE}

Metode Libqual+TM, metode yang digunakan untuk mengukur kepuasan pemustaka melalui fasilitas yang ada di perpustakaan Dinas Perpustakaan dan Kearsipan Kota Solok.

Terdapat tiga dimensi yang ada dalam Metode Libqual+TM yaitu Affect 
of Service (kinerja petugas dalam pelayanan), Information Control (kualitas informasi dan akses informasi), dan Library as Place (sarana perpustakaan).

Menurut Suharsimi Arikunto (2013) populasi subjek yang ada dalam penelitian secara keseluruhan. Dalam penelitian ini populasinya adalah anggota perpustakaan atau pengguna perpustakaan dimana peneliti akan menggunakan cara awal yaitu studi kasus pada perpustakaan atau dengan menyebarkan kuesioner terhadap pemustaka di Dinas Perpustakaan dan Kearsipan Kota Solok. Sedangkan sampel adalah bagian tertentu dari keseluruhan objek yang diteliti. Dalam penelitian ini yang menjadi populasi adalah seluruh anggota perpustakaan Dinas Perpustakaan dan Kearsipan Kota Solok. Penelitian ini mengambil jumlah populasi dari anggota perpustakaan di Dinas Perpustakaan dan Kearsipan Kota Solok yang berjumlah 8.126 orang sampai tahun 2020.

Teknik pengumpulan data berupa wawancara dan kuesioner.
Wawancara dilakukan kepada dua orang informan yang berbeda, pegawai di Dinas Perpustakaan dan Kearsipan Kota Solok dan lima orang pemustaka di Dinas Perpustakaan dan Kearsipan Kota Solok. Dalam penelitian ini, penulis menggunakan kuesioner tertutup agar memudahkan sampel dalam memberikan jawaban serta jawaban yang diberikan sampel akan bernilai sistematis dan akurat.

Terdapat tiga istilah dalam Metode LibQual+TM yang akan digunakan dalam analisis penelitian yaitu: (1) AG yaitu Adequacy Gap adalah nilai selisih yang diperoleh dari persepsi (P) - harapan minimum (HM). Skor AG akan bernilai positif apabila layanan yang diberikan telah memenuhi kebutuhan pemustaka, artinya pemustaka "cukup puas" dengan layanan yang diterima. Skor AG akan bernilai negatif apabila layanan yang diberikan belum memenuhi harapan pemustaka, dapat diartikan pula bahwa pemustaka "tidak puas" terhadap layanan yang diterimanya. (2) SG yaitu Superiority Gap adalah nilai selisih yang diperoleh dari persepsi (P) 
- harapan ideal (HI). Skor SG akan bernilai positif apabila layanan yang diberikan kepada pemustaka telah melebihi harapan pemustaka, dapat diartikan bahwa pemustaka "sangat puas" dengan layanan yang diterimanya. Skor SG akan bernilai negatif apabila kualitas layanan berada diantara Zone of Tolerance. (3) Zone of Tolerance adalah kualitas layanan yang dapat diterima dan tingkat minimum (HM) dengan harapan yang diinginkan (HI).

$$
\begin{array}{ll}
\text { Rumus : } & \mathrm{AG}=\mathrm{P}-\mathrm{HM} \\
\mathrm{SG}=\mathrm{P}-\mathrm{H}
\end{array}
$$

\section{HASIL DAN PEMBAHASAN}

Kepuasan Pemustaka di Dinas Perpustakaan dan Kearsipan Kota Solok dalam Analisis Dimensi Affect of Service. Kepuasaan pemustaka pada dimensi kinerja petugas dalam melayani (affect of service) dapat dilihat dari aspek empathy (rasa peduli), responsiveness (siap/tanggap membantu), assurance (kepastian), reliability (keandalan). Dimensi affect of service dikembangkan dalam beberapa pernyataan yang teridri dari 8 butir pernyataan.
Berdasarkan hasil penelitian yang diperoleh di Dinas Perpustakaan dan Kearsipan Kota Solok terhadap harapan minimum (HM), harapan ideal (HI), dan persepsi (P) menunjukkan bahwa dimensi affect of service pemustaka cukup puas karena telah memenuhi kebutuhan minimal pemustaka dengan Adequacy Gap (AG) bernilai positif dengan nilai 0,05 dan Superiority Gap (SG) bernilai positif dengan nilai 0,52 dimana angka ini menunjukkan bahwa pemustaka merasa sangat puas karena telah terpenuhi kebutuhannya.

Adequacy Gap (AG) tertinggi berada pada pustakawan memberikan perhatian kepada pemustaka yang kesulitan dalam melakukan pencarian informasi di perpustakaan dengan nilai 0,52. Menurut Rahayuningsih (2015) empathy atau rasa peduli dan memberi rasa penuh perhatian kepada setiap individu pengguna. Pemustaka yang ada di perpustakaan berhak meminta dan menerima layanan yang diberikan oleh pustakawan dalam bentuk perhatian, kepedulian dan kepekaan agar pemustaka merasa dihargai dan dianggap ada di dalam perpustakaan. 
Hal ini merupakan bagian dari keterampilan yang harus dimiliki sebagai seorang pustakawan. Pustakawan dapat memberikan layanan melalui perhatian berupa pentunjuk bagi pemustaka yang mengalami kesulitan. Selain itu, pemustaka juga merasa keberadaannya dianggap ada di perpustakaan tersebut. Dengan demikian, pemustaka akan cenderung untuk datang kembali ke perpustakaan. Hal ini juga dapat mempengaruhi citra perpustakaan.

Superiority Gap (SG) tertinggi berada pada waktu layanan sesuai dengan jam buka atau tutup perpustakaan dengan nilai 0,92 . Hal ini menunjukaan, bahwa antara presepsi dan harapan ideal yang diinginkan pemustaka sesuai. Layanan yang diberikan oleh perpustakaan sesuai dengan yang diharapan pemustaka. Waktu layanan yang sesuai akan membuat layanan yang diberikan oleh perpustakaan maksimal.

$$
\text { Selain memiliki tingkat }
$$
kepuasan pemustaka yang tinggi melalui perolehan nilai yang tinggi, dimensi affect of service juga memiliki nilai Adequacy Gap (AG) dan Superiority Gap (SG) terendah yang merupakan kekurangan yang dimiliki oleh perpustakaa, sehingga tingkat kepuasan pemustaka menjadi kurang. Adequacy Gap (AG) berada pada pustakawan memahami kebutuhan pemustaka di perpustakaan yang bernilai -0,48. Aspek yang ada pada dimensi affect of service yang lebih mendekati yaitu aspek empathy. Menurut Rahayuningsih (2015) aspek empathy yaitu rasa peduli dan memberi rasa penuh perhatian kepada setiap individu pengguna. Tidak adanya rasa peduli dan perhatian dari pustakawan akan mengakibatkan pemustaka merasa tidak puas dengan harapan yang diinginkannya seperti pustakawan tidak memiliki kecakapan dalam memperdulikan keinginan pemustaka untuk memberikan koleksi yang dibutuhkan dan tidak ada keinginan untuk melihat bagaimana harapan dari pemustaka tersebut.

Namun, pada kenyataannya pemustaka di Dinas Perpustakaan dan Kearsipan Kota Solok merasa tidak puas dalam bagian pustakawan kurang 
peduli dan kurang perhatian dalam memenuhi kebutuhan pemustaka, serta kurang cakap dan kurang tanggap dalam memperhatikan kemauan pemustaka. Kecakapan disini yaitu kesanggupan pustakawan memenuhi keinginan maupun harapan dari pemustaka dalam segi mendahulukan kepentingan pemustaka seperti pencarian bahan koleksi, melayani pemustaka dengan ramah, memperhatikan sikap pemustaka, dan mengambil alih kesulitan yang dialami oleh pemustaka. Untuk mengatasi hal tersebut perpustakaan perlu mengadakan pelatihan bagi pustakawan agar lebih peduli dan lebih sigap dalam melayani pemustaka. Hal ini guna untuk menjaga loyalitas pemustaka untuk mengunjungi perpustakaan kembali.

SG terendah berada pada pustakawan memahami kebutuhan pemustaka di perpustakaan bernilai negatif dengan skor -0,14. Menurut Fatmawati (2013) empati atau kepedulian dimana pustakawan memberikan perhatian yang bersifat individual atau pribadi kepada pemustaka untuk memahami kebutuhan atau keinginan pemustaka. Tidak adanya perhatian yang diberikan oleh pustakawan kepada pemustaka disaat pemustaka menggunakan perpustakaan akan memberikan rasa tidak puas terhadap pemustaka. Pemustaka akan merasa puas jika pustakawan dapat memberikan perhatian khusus kepada pemustaka disaat pemustaka menggunakan perpustakaan. Situasi seperti ini, sebaiknya pustakawan di Dinas Perpustakaan dan Kearsipan Kota Solok memberikan perhatian lebih terhadap pemustaka saat pemustaka menggunakan perpustakaan. Perhatian tersebut bisa dengan melalui pertanyaan kepada pemustaka mengenai informasi yang dibutuhkan oleh pemustaka atau hal lain yang diinginkan pemustaka. Hal ini juga dapat menjadi nilai tambahan untuk perpustakaan, karena mendapatkan citra yang baik dari pemustaka. Hal lain yang dapat diberikan oleh pustakawan yaitu dapat mengenali kepribadian pemustaka, sehingga pustakawan bisa lebih peka terhadap sikap pemustaka 
Published by Program Studi Perpustakaan dan Ilmu Informasi FBS Universitas Negeri Padang, Indonesia

saat menggunakan perpustakaan. Serta pustakawan dapat melayani pemustaka dengan ramah dan sopan agar pemustaka dapat leluasa menggunakan perpustakaan sesuai dengan kebutuhan yang dicari oleh pemustaka.

Kepuasan Pemustaka di Dinas Perpustakaan dan Kearsipan Kota Solok Analisis Dimensi Information Control. Kepuasan pemustaka pada dimensi Information Control (kualitas informasi dan akses informasi), yaitu ketersediaan informasi dan akses informasi yang berkualitas terdiri dari aspek Scope (cakupan informasi), Convenience (kenyamanan pemustaka dalam mengakses), Easy of Navigation (kemudahan pemustaka untuk mengakses informasi), Timelines (kecepatan pemustaka dalam mengakses informasi), Equipment (peralatan pemustaka untuk mengakses informasi) dan Self Reliance (kepercayaan dalam memanfaatkan fasilitas perpustakaan). Menurut Fatmawati, (2013) aspek personal control dan information acces adalah konsep yang membuat pemustaka dapat melakukan sendiri apa yang diinginkannya dalam mencari informasi tanpa bantuan pustakawan. Hal ini menyangkut tentang kemudahan navigasi, kenyamanan, peralatan, dan kepercayaan diri serta tentang ketersediaan bahan perpustakaan yang memadai, kekuatan koleksi/bahan pustaka yang dimiliki, cakupan isi/ruang lingkup, aktualitas, bimbingan pustakawan, maupun tingkat kecepatan waktu akses informasi di perpustakaan. Jika dilihat dari perkembangan pada tahun 2003 s.d. 2009 baru muncul istilah dimensi Information Control bermaksud sebagai alat yang mudah dioperasikan dan berguna untuk membantu pemustaka dalam menemukan sesuatu yang diingikan. Dimensi Information Control dikembangkan dalam beberapa pernyataan yang terdiri dari 14 butir pernyataan.

Berdasarkan hasil penelitian yang diperoleh di Dinas Perpustakaan dan Kearsipan Kota Solok terhadap harapan minimum (HM), harapan ideal (HI), dan persepsi (P) menunjukkan bahwa dimensi Information Control pemustaka belum puas karena belum 
Published by Program Studi Perpustakaan dan Ilmu Informasi FBS Universitas Negeri Padang, Indonesia

memenuhi kebutuhan minimal pemustaka dengan Adequacy Gap (AG) bernilai negatif dengan nilai $-0,20$ dan Superiority Gap (SG) bernilai positif dengan nilai 0,25 dimana angka ini menunjukkan bahwa pemustaka merasa sangat puas karena telah terpenuhi kebutuhannya.

Adequacy Gap (AG) tertinggi berada pada kemudahan pemustaka dalam menelusuri informasi di perpustakaan bernilai positif dengan nilai 0,12 . Hal ini menunjukkan bahwa pemustaka memperoleh layanan yang baik untuk memenuhi kebutuhan informasinya. Dengan demikian pemustaka akan merasa kebutuhan informasinya dapat dipenuhi dengan baik oleh Dinas Perpustakaan dan Kearsipan Kota Solok mampu memberikan layanan. Sedangkan Superiority Gap (SG) tertinggi pada kemudahan penggunaan Inlist untuk mencari informasi di perpustakaan dengan nilai 0,54. Hal ini sejalan dengan Adequacy Gap (AG) yang bernilai positif. Dua hal tersebut memiliki tujuan yang sama yaitu memberikan kemudahan bagi pemustaka dalam memenuhi kebutuhan informasi pemustaka. Kemudahan pemustaka dalam mendapatkan informasi atau dalam penelusuran informasi salah satunya dibantu dengan adanya penggunaan Inlist untuk mencari informasi yang dibutuhkan.

$$
\text { Selain memiliki tingkat }
$$
kepuasan pemustaka yang tinggi melalui perolehan nilai yang tinggi, dimensi information control juga memiliki nilai Adequacy Gap (AG) dan Superiority Gap (SG) terendah yang merupakan kekurangan yang dimiliki oleh perpustakaan, sehingga tingkat kepuasan pemustaka menjadi kurang. Adequacy Gap (AG) berada pada tersedianya tempat fotocopy di perpustakaan untuk memudahkan pemustaka mendapatkan bahan koleksi yang diinginkan. Pernyataan ini memiliki nilai negatif yaitu $-0,92$. Hal ini menunjukkan bahwa tingkat kepuasan pemustaka terhadap layanan fotocopy yang disediakan oleh Dinas Perpustakaan dan Kearsipan Kota Solok adalah baik. Perolehan nilai tersebut sebaiknya dapat dijadikan pedoman 
bagi Dinas Perpustakaan dan Kearsipan

Kota Solok untuk lebih meningkatkan layanan dalam meyediakan tempat fotocopy. Ketersediaan tempat fotocopy bertujuan agar pemustaka terbantu jika membutuhkan koleksi atau bahan pustaka yang tidak dapat dipinjam untuk dibawa pulang. Sedangkan Superiority Gap (SG) terendah pada pernyataan yang sama dengan nilai 0,74 . Hal ini menunjukkan harapan presepsi dan harapan ideal yang diinginkan pemustaka tidak sesuai.

\section{Library as Place. Kepuasan} pemustaka pada dimensi library as place menurut Fatmawati (2013) perpustakaan dianggap sebagai sebuah tempat yang mempunyai kemampuan untuk menampilkan sesuatu secara nyata berupa fasilitas fisik (physical facilities), bagaimana perpustakaan dalam memanfaatkan ruang, peralatan/perabotan (equipment), ketersediaan sarana peralatan komunikasi dan petugas (personnel and communication materials), maupun sebagai simbol dan tempat perlindungan. Konsep library as place digunakan untuk menilai kemampuan perpustakaan dalam memenuhi harapan pemustaka dalam penyediaan berbagai fasilitas di perpustakaan. Dimensi library as place dikembangkan dalam beberapa pernyataan yang teridri dari 8 butir pernyataan.

Berdasarkan hasil penelitian yang diperoleh di Dinas Perpustakaan dan Kearsipan Kota Solok terhadap harapan minimum (HM), harapan ideal (HI), dan persepsi (P) menunjukkan bahwa dimensi library as placepemustaka cukup puas karena telah memenuhi kebutuhan minimal pemustaka dengan Adequacy Gap (AG) bernilai negatif dengan nilai 0,13 dan Superiority Gap (SG) bernilai positif dengan nilai 0,50 dimana angka ini menunjukkan bahwa pemustaka merasa sangat puas karena telah terpenuhi kebutuhannya.

$$
\text { Adequacy Gap (AG) tertinggi }
$$

berada pada perpustakaan merupakan tempat yang tenang sehingga pemustaka dapat konsentrasi dalam belajar dengan nilai 0,42. Hal ini menunjukkan bahwa pemustaka mendapatkan kenyamanan ketika berada dalam ruangan perpustakaan 
Dinas Perpustakaan dan Kearsipan Kota Solok. Kenyamanan tersebut juga dapat mempengaruhi tingkat kepuasan pemustaka terhadap layanan yang diberikan. Semakin pemustaka merasa nyaman, maka semakin tinggi tingkat kepuasan pemustaka. Selain itu, kenyamanan yang diperoleh oleh pemustaka juga dapat memberikan citra positif bagi Dinas Perpustakaan dan Kearsipan Kota Solok. Sedangkan Superiority Gap (SG) tertinggi pada perpustakaan dalam kondisi yang bersih sehingga nyaman untuk belajar dengan nilai 0,64. Hal ini sejalan dengan perpustakaan merupakan tempat yang tenang sehingga pemustaka dapat konsentrasi dalam belajar. Dengan demikian harapan presepsi dan harapan ideal yang diinginkan pemustaka tidak sesuai.

Selain memiliki tingkat kepuasan pemustaka yang tinggi melalui perolehan nilai yang tinggi, dimensi library as place juga memiliki nilai Adequacy Gap (AG) dan Superiority Gap (SG) terendah yang merupakan kekurangan yang dimiliki oleh perpustakaa, sehingga tingkat kepuasan pemustaka menjadi kurang. Adequacy Gap (AG) terendah berada pada desain perpustakaan yang menarik pemustaka sebagai tempat diskusi. Pernyataan ini memiliki nilai negatif yaitu $-0,12$. Hal ini menunjukkan bahwa tingkat kepuasan pemustaka terhadap desain perpustakaan masih belum puas. Desain perpustakaan juga dapat mempengaruhi tingkat kenyamanan pemustaka yang dilihat dari nilai estetika, sehingga juga dapat berpengaruh pada tingkat kepuasan pemustaka. Dinas Perpustakaan dan Kearsipan Kota Solok sebaiknya lebih memperhatikan desain perpustakaan ini, salah satunya penempatan ruang diskusi serta interior pendukung lainnya.

Sedangkan, Superiority Gap (SG) terendah pada perpustakaan merupakan tempat yang tenang sehingga pemustaka dapat konsentrasi dalam belajar dengan nilai 0,8. Ketenangan pemustaka ini juga berkaitan dengan penempatan ruangan, tingkat kebisingan, serta interior pendukung lainnya. Hal ini 
menunjukkan harapan presepsi dan harapan ideal yang diinginkan pemustaka tidak sesuai. Akan lebih baik Dinas Perpustakaan dan Kearsipan Kota Solok untuk dapat memperbaiki hal tersebut, sehingga memberikan kenyamanan dan ketenangan bagi pemustaka yang ingin membaca maupun diskusi di perpustakaan. Salah satu hal yang dapat dilakukan adalah pemilihan ruangan khusus, seperti menyediakan ruangan kedap suara.

\section{PENUTUP}

\section{Simpulan}

Berdasarkan hasil hitung dan pembahasan yang diuraikan maka dapat disimpulkan tingkat kepuasan pemustaka Dinas Perpustakaan dan Kearsipan Kota Solok yang dianalisis menggunakan Libqual ${ }^{+\mathrm{TM}}$ yang terdiri dari tiga dimensi yaitu affect of service, information control, dan library as place. Dari hasil hitung ketiga dimensi tersebut diperoleh hasil sebagai berikut: (1) berdasarkan dimensi kinerja petugas dalam melayani (affect of service) pemustaka merasakan cukup puas dengan Adequacy Gap (AG) dimensi bernilai positif dengan skor 0,05 dan tingkat kepuasan pemustaka terhadap perpustakaan dinilai sangat puas dengan Superiority Gap (SG) bernilai positif dengan skor 0,52; (2) berdasarkan dimensi kualitas informasi dan akses informasi (information control) pemustaka belumpuas dengan Adequacy Gap (AG) dimensi bernilai negatif dengan skor $-0,20$ dan tingkat kepuasan pemustaka terhadap perpustakaan dinilai sangat puas dengan Superiority Gap (SG) bernilai positif dengan skor 0,25; (3) berdasarkan dimensi sarana prasarana perpustakaan (library as place) pemustaka cukup puas dengan Adequacy Gap (AG) dimensi bernilai dengan skor 0,013 dan tingkat kepuasan pemustaka terhadap perpustakaan dinilai sangat puas dengan Superiority Gap (SG) bernilai positif dengan skor 0,50. Secara keseluruhan tingkat kepuasan pemustaka di Dinas Perpustakaan dan Kearsipan Kota Solok pemustaka cukup puas dengan rata-rata Adequacy Gap (AG) bernilai positif dengan skor 0,08 dan tingkat kepuasan pemustaka 


\section{Info Bibliotheca}

terhadap perpustakaan dinilai sangat puas dengan rata-rata Superiority Gap (SG) bernilai positif dengan skor 0,4.

\section{Saran}

Berdasarkan kesimpulan yang telah diuraikan penulis memberikan beberapa saran sebagai berikut. Pertama, hasil penelitian ini dapat dijadikan sebagai pedoman untuk penelitian selanjutnya dengan menggunakan metode lain ataupun metode Libqual+TM yang dikembangkan lagi. Kedua, kekurangan yang terdapat dalam penelitian ini dapat disempurnakan oleh penelitian selanjutnya mengenai tingkat kepuasan pemustaka menggunakan metode Libqual+TM. Ketiga, Dinas Perpustakaan dan Kearsipan Kota Solok dapat melakukan perubahan ataupun perbaikan untuk meningkatkan layanan terhadap pemustaka terutama yang berhubungan dengan ketiga dimensi yaitu, affect of service, information control, dan library as place.

\section{DAFTAR PUSTAKA}

Ajat, R. (2018). Pendekatan Penelitian Kuantitatif: Quantitative Research
Approach. In Deepublish. https://books.google.co.id/metod e deskriptif menurut nazir

Al-Ghazali. (2019). Wawancara 4. 2027.

https://doi.org/10.31219/osf.io/

2 mqxg

Amalia Okta Nur, L. C. (2020). Analisis Tingkat Kepuasan Pemustaka terhadap Kualitas Pelayanan Perpustakaan dengan Metode LibQual+TM (Studi Kasus di Perpustakaan Politeknik

Kementerian Kesehatan

Semarang). 9(2), 33-41.

Andriani, D. (2018). Pengaruh Fasilitas Perpustakaan terhadap Minat Baca Siswa SMK N 4 Makassar. Journal of Physical Therapy Science, $\quad 9(1), \quad 1-11$. http://dx.doi.org/10.1016/j.neur opsychologia.2015.07.010\%0Ahtt p://dx.doi.org/10.1016/j.visres.2 014.07.001\%0Ahttps://doi.org/1 0.1016/j.humov.2018.08.006\%0A http://www.ncbi.nlm.nih.gov/pu bmed/24582474\%0Ahttps://doi. org/10.1016/j.gaitpost.2018.12.0 


\section{Info Bibliotheca}

07\%0Ahttps:

Cipta, H., Lindungi, D., Mengutip, D., Medan, U., Document, A., \& From, A. (2019). Perpustakaan Umum di Kota Medan Skripsi Disusun Oleh: Sunaryo Aritonang Program Studi Arsitektur Fakultas Teknik Universitas Medan Area Medan 2019 Skripsi Disusun Untuk Memenuhi Tugas Dan Sebagai Salah Satu Syarat Untuk Memproleh Gelar Sarjana di Fakultas.

Faidah, A. N., \& Rachman, M. Y. (2016). Analisis kualitas pelayanan dengan metode libqual. 60-69.

Fatimah. (2018). Pperpustakaan, Manfaat, Kelebihan dan Kekurangan. Jurnal Imam Bonjol, 2(1), 30-35.

Fatmawati, E. (2013). Matabaru Penelitian Perpustakaan Dari SERVQUAL ke LibQUAL ${ }^{+T M}$. Sagung Seto.

http://journal.ipb.ac.id/index.php /jpi/article/view/9511

Ferdiyanto, D. (2012). Pengaruh
Fasilitas Perpustakaan dan Pelayanan Pustakawan terhadap minat baca masyarakat di Perpustakaan Daerah Kabupaten Boyolali. Perpustakaan.Uns.Ac.Id, 32.

Hidayat, N., Thabrani, G., Padang, U. N., Utara, P., Padang, K., Barat, S., Padang, U. N., Utara, P., Padang, K., Barat, S., Padang, U. N., Utara, P., Padang, K., Barat, S., \& Deployment, Q. F. (2018). Analisis Peningkatan Kualitas Pelayanan Di Perpustakaan Universitas Negeri Padang (Unp) Dengan. Journal of Multidisciplinary Research and Development, 1(1), 28-39.

Irianti, P. (2017). Kepuasan Pemustaka Terhadap Fasilitas Perpustakaan di Fakultas Psikologi Universitas Gadjah Mada. Berkala Ilmu Perpustakaan Dan Informasi, 13(1), 47. https://doi.org/10.22146/bip.16 757

M. Reza Rokan. (2017). Manajemen Perpustakaan Sekolah. Jurnal 


\section{Info Bibliotheca}

Iqra', 11(01), 88-100.

Mangnga, A. (2015). Peran

Perpustakaan Sekolah Terhadap

Proses Belajar Mengajar Di

Sekolah. Jupiter, XIV(1), 38-42.

http://journal.unhas.ac.id/index.p

hp/jupiter/article/view/27

Najah, N. A. (2015). Hubungan dukungan sosial dengan tingkat stres di sekolah pada siswa akselerasi MAN Denanyar Jombang. Journal of Chemical Information and Modeling, 53(9), 1689-1699. http://etheses.uinmalang.ac.id/id/eprint/1578

Rahayuningsih, F. (2015). Mengukur

Kepuasan

Pemustaka

Menggunakan Metode

LibQual+TM. Graha Ilmu.

Rakib, F. A. (2013). Kepuasan Pemustaka Terhadap Layanan Perpustakaan Keliling Terapung (Studi Kasus di Kota Ternate). Journal Volume II. No. 4. Tahun 2013, II(4), 19.

RI, U.-U. (2007). Undang-Undang RI No.43 Tahun 2007 tentang perpustakaan. UU RI No.43 Th. 2007, 3(September).

Saleh, Abdul Rahman; Komalasari, R. (2014). Pengertian Perpustakaan dan Dasar-dasar Manajemen Perpustakaan. In Manajemen Perpustakaan (pp. 1-45). Universitas Terbuka.

Santoso, N. H. D. (2012). Analisis Pengaruh Product Quality, Perceived Quality, Perceived Value dan Promotion Terhadap Kepuasan Pelanggan.

Sarwono, S., Isbandini, I., \& Rahayu, D. (2018). Analisis Tingkat Kepuasan Pemustaka Terhadap Layanan Electronic Theses and Dissertations (ETD) Perpustakaan UGM dengan Menggunakan Metode LibQUAL +TM. LIBRARIA: Jurnal Perpustakaan, 6(2), 299. https://doi.org/10.21043/librari a.v6i2.4153

Sefko Bintang Guntara, N. S. (2013). PENGARUH PENGOLAHAN KOLEKSI, KOMPETENSI PENGELOLA, DAN FASILITAS 


\section{Info Bibliotheca}

Jurnal Perpustakaan dan Ilmu Informasi

Published by Program Studi Perpustakaan dan IImu Informasi FBS Universitas Negeri Padang, Indonesia

PERPUSTAKAAN

TERHADAP

KUALITAS

PELAYANAN

PERPUSTAKAAN. 2(1), 18-23.

Simarmata, L., Osak, R. E. M. ., Endoh, E. K. ., \& Oroh, F. N. . (2019). Analisis Preferensi Konsumen Dalam Membeli Daging Broiler Di Pasar Tradisional Kota Manado (Studi Kasus "Pasar Pinasungkulan Karombasan"). Zootec, 39(2), 194-202.

Sirdawati dkk. (2017). Persepsi pemustaka terhadap kualitas layanan berdasarkan analisis libqual. Jurnal Ilmu Komunikasi UHO, 2(2).

Suharsimi Arikunto. (2013). Prosedur Penelitian Suatu Pendekatan Praktek. Rineka Cipta. http://perpustakaan.bppsdmk.ke mkes.go.id//index.php?p=show_d etail\&id=3452

Supardi. (2017). Statistik Penelitian Pendidikan: Perhitungan, Penyajian, Penjelasan, Penafsiran, dan Penarikan Kesimpulan. Rajawali Pers.
Waspodo, A. A., Handayani, N. C., \& Paramita, W. (2013). Pengaruh Kepuasan Kerja dan Stres Kerja terhadap Turnover Intention pada Karyawan PT. Unitex di Bogor. Jurnal Riset Manajemen Sains Indonesia (JRMSI), 4(1), 97-115.

Widiasa, I. K. (2007). Manajemen Perpustakaan Sekolah. Jurnal Perpustakaan Sekolah, 1(6), 1-14. http://library.um.ac.id/images/g bjps/art02ktu.pdf

Yusup, F., Studi, P., Biologi, T., Islam, U., \& Antasari, N. (2018). Uji Validitas dan Reliabilitas. 7(1), 17-23. 